EWERTON LUCENA FERREIRA

\title{
DESENVOLVIMENTO DE UMA NOVA ESTRATÉGIA VACINAL CONTRA A CÁRIE DENTAL HUMANA BASEADA NA PROTEÍNA PstS DE Streptococcus mutans.
}

Dissertação apresentada ao Programa de Pós-Graduação em Microbiologia do Instituto de Ciências Biomédicas da Universidade de São Paulo, para obtenção do título de Mestre em Ciências.

Área de Concentração: Microbiologia

Orientadora: Profa. Dra. Rita de Cássia Café Ferreira

Versão original 


\section{RESUMO}

FERREIRA, E. L. Desenvolvimento de uma nova estratégia vacinal contra a cárie dental humana baseada na proteína PstS de Streptococcus mutans. 2015. 63 f. Dissertação de (Mestrado em Microbiologia) - Instituto de Ciências Biomédicas, Universidade de São Paulo, São Paulo, 2015.

Streptococcus mutans é o principal agente etiológico da cárie dental humana, uma doença infecciosa com ampla distribuição mundial, para a qual não há vacina disponível apesar do conhecimento de importantes fatores envolvidos na virulência. A influência dos sistemas de transporte do tipo ABC (ATP-Binding Cassete) na virulência bacteriana suporta o uso de componentes desses sistemas como alvos promissores em estratégias vacinais. Em $S$. mutans a proteína ligadora de fosfato inorgânico (PstS) exerce influência na expressão de fatores associados à virulência. Assim, a proposta deste trabalho foi a caracterização imunológica de uma nova estratégia vacinal de mucosa anti-cárie baseada na proteína PstS de $S$. mutans como antígeno alvo. Inicialmente, a forma recombinante da proteína PstS foi obtida no estado solúvel em Escherichia coli. A caracterização biofísica da proteína rPstS purificada revelou uma estrutura secundária estável e semelhante a de outras proteínas ligadoras, além da capacidade de interação com seu ligante. Epítopos antigênicos conservados, conformacionais e lineares, foram identificados na proteína recombinante pela reatividade com soro gerado contra células intactas de $S$. mutans. Foi possível determinar a imunogenicidade da proteína rPstS quando administrada por via sublingual, combinada ou não a um adjuvante derivado da toxina termo-lábil (LTK4R) de Escherichia coli enterotoxigênica (ETEC). Respostas humorais, sérica e de mucosa, foram estimuladas pela vacina e anticorpos rPstS-específicos interferiram na colonização oral in vivo por S. mutans em modelo murino. Em conjunto, os resultados obtidos indicam que a proteína rPstS preserva características estruturais e imunológicas da proteína nativa que podem ser exploradas em estratégias vacinais para o controle da cárie dental.

Palavras-chave: Streptococcus mutans. Cárie dental. Vacinas. PstS. Vacinas de mucosa. Imunização sublingual. 


\begin{abstract}
FERREIRA, E. L. Development of a new vaccine strategy against human dental caries based on the PstS protein of Streptococcus mutans. 2015. 63 p. Master thesis (Microbiology) - Instituto de Ciências Biomédicas, Universidade de São Paulo, São Paulo, 2015.
\end{abstract}

Streptococcus mutans is the main etiological agent of human dental caries, an infectious disease worldwide distributed, for which there is no vaccine available despite the knowledge of important virulence-associated factors. The influence of ABC (ATP-Binding Cassete) transport systems in bacterial virulence supports the use of components of these systems as promising targets in vaccine approaches. In S. mutans the phosphate binding protein (PstS) influences the expression of virulence-associated traits. Thus, the main purpose of this work was the immunological characterization of a new anti-caries mucosal vaccine approach based on the PstS of $S$. mutans as target antigen. First, a recombinant soluble PstS form was obtained inEscherichia coli. The biophysical characterization of the purified rPstS protein showed a stable secondary structure, similar to other binding proteins, and retained ability to interact with its ligand. Conserved antigenic epitopes, including conformational and linear epitopes, were identified in the recombinant protein by reactivity with serum raised against intact $S$. mutans cells. The immunogenicity of the rPstS protein was determined after administration via the sublingual route in combination with an adjuvant derived from the heat-labile toxin (LTK4R) of enterotoxigenic Escherichia coli (ETEC).Mucosal and systemic antibody responses were stimulated by this vaccine and the rPstS-specific antibodies interfered with $S$. mutans oral colonization in vivo in a murine model. Taken together, the results indicated that the recombinant PstS protein preserves structural and immunological characteristics of the native protein that can be exploited in vaccine strategies for the control of dental caries.

Key words: Streptococcus mutans. Dental caries. Vaccines. PstS. Mucosal vaccines. Sublingual immunization. 


\section{INTRODUÇÃO}

\subsection{Streptococcus mutans e a cárie dental}

O gênero Streptococcus compreende espécies bacterianas Gram-positivas, catalasenegativas, arranjadas em cadeia e relacionadas a diferentes processos infecciosos em humanos. A espécie Streptococcus mutans é imóvel, anaeróbia facultativa e capnofílica, possui a capacidade de metabolizar diferentes carboidratos e sintetizar glucanos aderentes solúveis em água, o que lhe confere ainda a habilidade de aderir a superfícies lisas. Dentro do gênero, esta espécie está enquadrada no grupo Mutans, que compreende outras bactérias colonizadoras da cavidade oral de mamíferos, sendo frequentemente designadas como grupo viridans, pelo padrão de $\alpha$-hemólise das colônias em ágar sangue. Além disso, S. mutans é o principal agente infeccioso relacionado ao desenvolvimento da cárie dental na espécie humana e também é associada a casos de endocardite bacteriana (BANAS, 2004; NOBBS et al., 2009).

A cárie dental é o resultado da dissolução localizada do tecido calcificado do dente pela produção de ácidos por bactérias presentes no biofilme dental. É uma das doenças mais comuns em humanos e tem atingido proporções epidêmicas em países desenvolvidos e subdesenvolvidos. O estabelecimento da cárie depende da influência de múltiplos fatores, como a susceptibilidade e dieta rica em açúcar do hospedeiro, além de uma microbiota cariogênica capaz de produzir ácidos a partir dos carboidratos da dieta, todos esses fatores associados ao tempo (SHIVAKUMAR et al., 2008). Diferentes microrganismos estão presentes na placa dental e são identificados em lesões cariogênicas, no entanto $S$. mutans é a espécie mais prevalente e mais cariogênica, devido ao seu papel na biossíntese da matriz do biofilme dental e pela sua capacidade de sobreviver frente a outras espécies em condições de baixo pH (LEMOS et al., 2013; SHIVAKUMAR et al., 2008).

Estudos acerca da biologia de S. mutans demonstraram a presença de fatores de virulência relacionados à patogenicidade da carie dental, como (i) a habilidade de adesão/produção de biofilme na superfície dental, (ii) a capacidade de produção de ácidos (acidogenicidade) a partir de componentes da dieta do hospedeiro e (iii) resistência ao $\mathrm{pH}$ ácido (aciduricidade) (HAMADA et al., 1984; MICHALEK et al., 1981). Essas características 
contribuem para o aumento da proporção de $S$. mutans no biofilme dental, o que leva a uma acentuada queda no $\mathrm{pH}$ e aumenta a probabilidade de desmineralização do esmalte dental (BANAS, 2004).

O processo de adesão e formação de biofilme é essencial para o desenvolvimento da carie dental, uma vez que permite o contato inicial da bactéria e seus produtos metabólicos à superfície do dente (HAMANDA et al., 1980). Esse processo envolve duas etapas: o primeiro estágio, sacarose-independente, mediado pela adesina bacteriana antígeno I/II (ou proteína SpaP, ou proteína P1) que interage com as proteínas salivares da película adquirida, mais precisamente a gp340, que recobre o esmalte do dente, garantindo o início do processo de fixação. No segundo estágio, sacarose-dependente, há a produção de glucanos insolúveis, denominados polissacarídeos extracelulares (PECs), produzidos pelas glicosiltransferases (Gtf) a partir da sacarose proveniente da dieta do hospedeiro. Essas estruturas interagem com as próprias Gtfs e adesinas ligadoras de glucano (GBPs), presentes na superfície da célula de S. mutans, estabelecendo a colonização da superfície dental (BANAS, 2004; HAMANDA et al., 1984; RUSSELL, 2006).

Além disso, S. mutans possui vias glicolíticas completas para produção de ácidos a partir de carboidratos e a velocidade com que produz esses ácidos supera a de outros estreptococos orais. Isto conduz a uma mudança na composição microbiana da placa dental, aumentando a proporção desta bactéria e de outras espécies acidogênicas e ácido tolerantes, o que por sua vez mantém o $\mathrm{pH}$ da placa baixo, favorecendo assim a desmineralização do esmalte dental. Somado a essa acidogenicidade, o S. mutans ainda consegue manter seu metabolismo nos baixos níveis de $\mathrm{pH}$ da placa dental e essa aciduricidade também é notavelmente distinta de outras espécies do gênero (BANAS, 2004).

A forma tradicional de lidar com a cárie é feita pela remoção da estrutura dental comprometida. Ao longo dos anos, medidas preventivas também foram adotadas, como uso de fluoreto na água, produtos com menor teor de açúcar, selantes e aumento do acesso à saúde bucal, com impacto positivo na redução no número de casos. No entanto, nos locais em que não se usa água fluoretada ou em que a população não tem acesso à saúde bucal, outras medidas preventivas se fazem necessárias, como a imunização da população através de vacinas, uma estratégia clássica na prevenção de doenças infecciosas (BANAS, 2004; SHIVAKUMAR et al., 2009). 


\subsection{Antígenos vacinais contra a cárie}

O conceito de imunização contra a cárie existe desde o momento em que se determinou que esta doença era o resultado da colonização do dente por bactérias acidogênicas. Tendo sido reconhecido que estreptococos do grupo mutans, especialmente $S$. mutans, eram os principais responsáveis pelo desencadeamento desta doença, este passou a ser o alvo das abordagens vacinais (RUSSELL et al., 2004; SMITH, 2010). A patogênese molecular de $S$. mutans no desenvolvimento da cárie envolve várias etapas que são passíveis de intervenção imune. A bactéria pode ser eliminada da cavidade oral ainda na fase salivar, por agregação mediada por anticorpos, estes ainda podem bloquear receptores necessários para colonização ou agregação, e ainda inativar enzimas responsáveis pela síntese do biofilme (SMITH, 2003).

Acredita-se que a resposta imune específica contra este patógeno seja dependente de anticorpos salivares, cujo principal é a imunoglobulina A na forma secretada (S-IgA), produto do sistema imune de mucosa, assim como da presença de IgG sistêmico presente no fluído crevicular. Os mecanismos de ação mediados por S-IgA, que ocorrem em outros sítios de mucosa, também podem ocorrer na cavidade oral, permitindo o bloqueio de adesinas e neutralização de fatores de virulência. Da mesma forma os anticorpos IgG plasmáticos disponíveis no fluido cervicular gengival poderiam contribuir com os mecanismos protetores contra S. mutans (RUSSELL et al., 1999; SHIVAKUMAR et al., 2009).

Algumas proteínas de superfície ou secretadas de $S$. mutans que participam da adesão ao dente e da produção e ligação ao glucano do biofilme dental foram propostas como possíveis antígenos vacinais. A adesina conhecida como Ag I/II ou P1, contém domínios de ligação à saliva em sua estrutura associados à capacidade de adesão ao dente. Anticorpos direcionados contra a proteína inteira ou específicos para o domínio de ligação à saliva foram capazes de interferir com a adesão de $S$. mutans, bloqueando as etapas iniciais de colonização no biofilme dental (SMITH, 2003, 2010).

As glucosiltransferases (GTFs) produzem glucanos solúveis e insolúveis em água, ambos contribuem para a segunda etapa de adesão de $S$. mutans, a sacarose-dependente, e para a cárie (BANAS, 2004). O crescimento de $S$. mutans em presença de anticorpos contra as Gtfs foi capaz de diminuir significativamente a quantidade de biofilme e estudos de imunização utilizando Gtfs como antígeno foram capazes de proteger os animais infectados 
com S. mutans, provavelmente pela interferência com as atividades funcionais destas enzimas na síntese de glucanos (SMITH, 2003). As proteínas ligadoras de glucano (Gbps) na superfície de S. mutans atuam como receptores para a agregação mediada por glucano, também no segundo estágio de adesão ao dente. Entre as quatro diferentes proteínas com atividade ligadora de glucano secretadas por S. mutans (GbpA, GbpB, GbpC e GbpD), apenas para GbpB se observou indução de resposta imune e eficácia em ensaios pré-clínicos com uma estratégia vacinal de subunidade (SMITH, 2004).

Em modelos animais esses antígenos foram capazes de induzir produção de $\operatorname{IgA}$ salivar e IgG sérica responsáveis pela inibição da formação de cárie e indução de imunidade protetora (RUSSELL et al., 1999, 2004; SMITH, 2010). Apesar da quantidade de evidências experimentais sobre a eficácia de estratégias vacinais contra a cárie dental, não existe nenhuma para uso em humanos. Melhorias nas abordagens vacinais, tem conduzido as pesquisas para a identificação de novos antígenos e adjuvantes de mucosa visando o desenvolvimento de vacinas anti-cárie eficazes (SMITH, 2003, 2010).

\subsection{Transportadores $\mathrm{ABC}$ como antígenos vacinais}

Sistemas de transporte são essenciais para a passagem de substâncias através do envoltório bacteriano, como os nutrientes necessários ao crescimento celular. Entre os sistemas de transporte dependentes de energia, destacam-se aqueles que dependem da hidrólise do ATP, como os transportadores do tipo ABC ( $\underline{A} T P \underline{B}$ inding $\underline{\text { Cassete }})$. Esses sistemas estão presentes nos três grandes reinos biológicos (Archea, Bacteria e Eukarya) e são utilizados tanto para captar, como para exportar diferentes substâncias (HIGGINS, 1992, 2001). Os sistemas importadores do tipo $\mathrm{ABC}$ são restritos às bactérias e archeas, sendo responsáveis pela captação de nutrientes como fosfato, oligopeptídeos, poliaminas, açúcares, nitrato, sulfato, ferro, molibdato e outros (LINTON et al., 1998).

Os sistemas do tipo $\mathrm{ABC}$, em geral, representam 5\% dos genomas bacterianos conhecidos e são constituídos por três componentes funcionais e estruturais (figura 1). Dois componentes apresentam-se associados à membrana citoplasmática, um formando um poro transmembrânico por onde a substância é transportada e o outro, associado à face interna da membrana, responsável por se ligar e hidrolisar o ATP, fornecendo a energia necessária para 
o transporte (MOUTRAN et al., 2003). O terceiro componente mostra-se solúvel e retido no periplasma nas bactérias gram-negativas ou associado à membrana citoplasmática nas bactérias gram-positivas e, portanto, exposto na superfície bacteriana. Esse componente tem como principal função o reconhecimento e a ligação ao substrato sendo responsável pela especificidade e pela afinidade do sistema a um determinado ligante (DASSA, 2000).

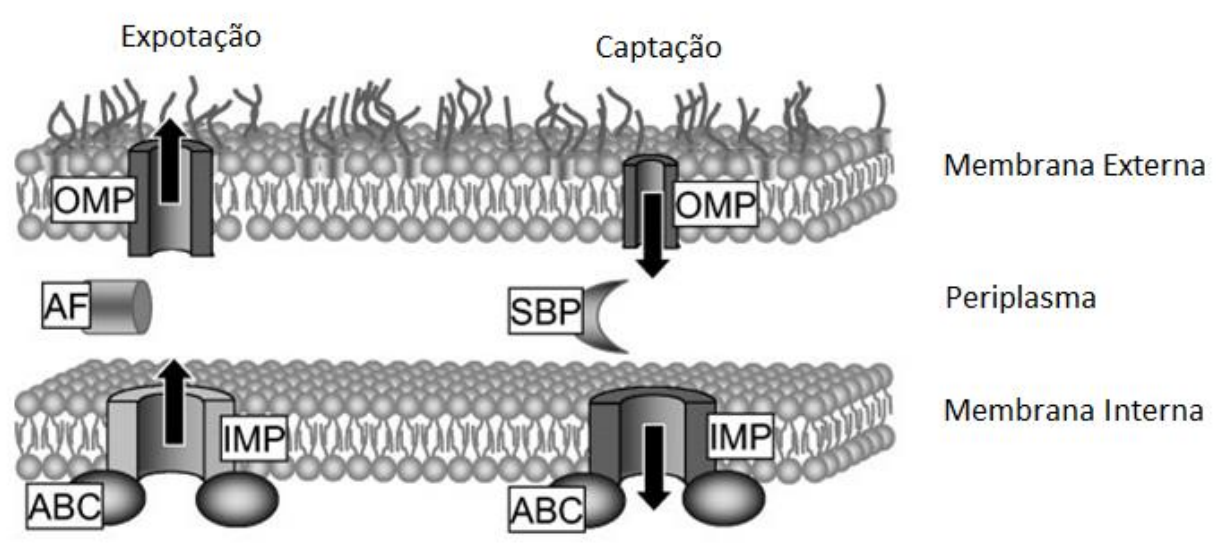

Figura 1. Organização típica de transportadores $\mathrm{ABC}$ em bactérias Gram-negativas. Os componentes IMP (Componente de membrana interna) e ABC (Cassete de ligação ao ATP) estão presentes nos dois tipos de sistema. Nos sistemas de captação a proteína ligadora (SBP) se liga especificamente à molécula que será internalizada. Em alguns sistemas de exportação existe um fator acessório (AF) que facilita a saída da molécula. As proteínas de membrana externa (OMP) auxiliam a entrada e saída de moléculas transportadas. Fonte: Adaptado de Garmory e Titball (2004).

Além do papel relacionado ao transporte de substâncias, os transportadores ABC também são capazes de influenciar direta ou indiretamente a expressão de fatores associados à virulência em espécies patogênicas ao homem. Em Streptococcus pneumoniae, Yersinia pestis e Staphylococcus aureus foi possível relacionar a ausência de determinados transportadores ABC de captação de nutrientes com atenuação da virulência. Da mesma forma, transportadores de ferro e manganês mostraram-se essenciais para a virulência de Yersinia pestis e Salmonella enterica serovar Typhimurium (GARMORY; TITBALL, 2004).

Devido ao importante papel na fisiologia e virulência bacteriana, os transportadores $\mathrm{ABC}$ vêm sendo investigados como possíveis alvos vacinais. Diferentes componentes de sistemas $\mathrm{ABC}$, sobretudo os componentes ligadores de substrato, revelaram ter elevada 
antigenicidade, indicando um possível papel desses transportadores como alvo para imunoterapia (GARMORY; TITBALL, 2004).

Algumas abordagens vacinais utilizando componentes de sistemas de transporte $\mathrm{ABC}$ foram testadas em modelos animais. Destacam-se o uso da proteína PstS de Mycobacterium tuberculosis, relacionada com o transporte de fosfato, das proteínas PiuA e PiaA de S.pneumoniae, envolvidas na captação de ferro e da proteína OppA de Y. pestis e Moraxella catarrhalis capazes de transportar uma variedade de peptídeos (BROWN et al., 2001; TANABE et al., 2006; TANGHE et al., 1999; YANG et al., 2011). Esses estudos demonstram que, além de imunogênicas, essas proteínas podem promover proteção vacinal em modelos experimentais de infecção.

Em S. mutans cerca de $10 \%$ do genoma é dedicado à codificação de transportadores ABC (AJDÍC et al., 2002). Estudos relacionados a esses transportadores nesta espécie são limitados e restringem-se a sistemas envolvidos na captação de polissacarídeos, maltose e ferro. Pesquisas recentes descreveram as características dos sistemas de captação de oligopeptídeos (NEPOMUCENO et al., 2007), glutamato (KRASTEL et al., 2010) e fosfato inorgânico, ou Pst, em S. mutans (LUZ et al., 2012).

\subsection{A proteína PstS como antígeno vacinal}

O sistema Pst possui papel importante na captação de fosfato inorgânico (Pi) necessário na biossíntese de ácidos nucléicos, fosfolipídeos e outros componentes celulares (VAN VEEN, 1997). Esse sistema é responsável pela captação de Pi em situações de carência de fosfato extracelular e em $S$. mutans UA159 é codificado pelo operon policistrônico pst, constituído de cinco genes estruturais (pst $\mathrm{S}, p s t \mathrm{C}$, pst $\mathrm{A}$, pst $\mathrm{B}$ e smu.1134). O gene pst $\mathrm{S}$ codifica a proteína ligadora de $\mathrm{Pi}$ que confere afinidade ao sistema, os genes pst $\mathrm{C}$ e pstA codificam os dois polipeptídeos que formam o canal transmembrânico e os genes pst $\mathrm{B}$ e smu.1134 codificam o componente de ligação e hidrólise do ATP (figura 2). 


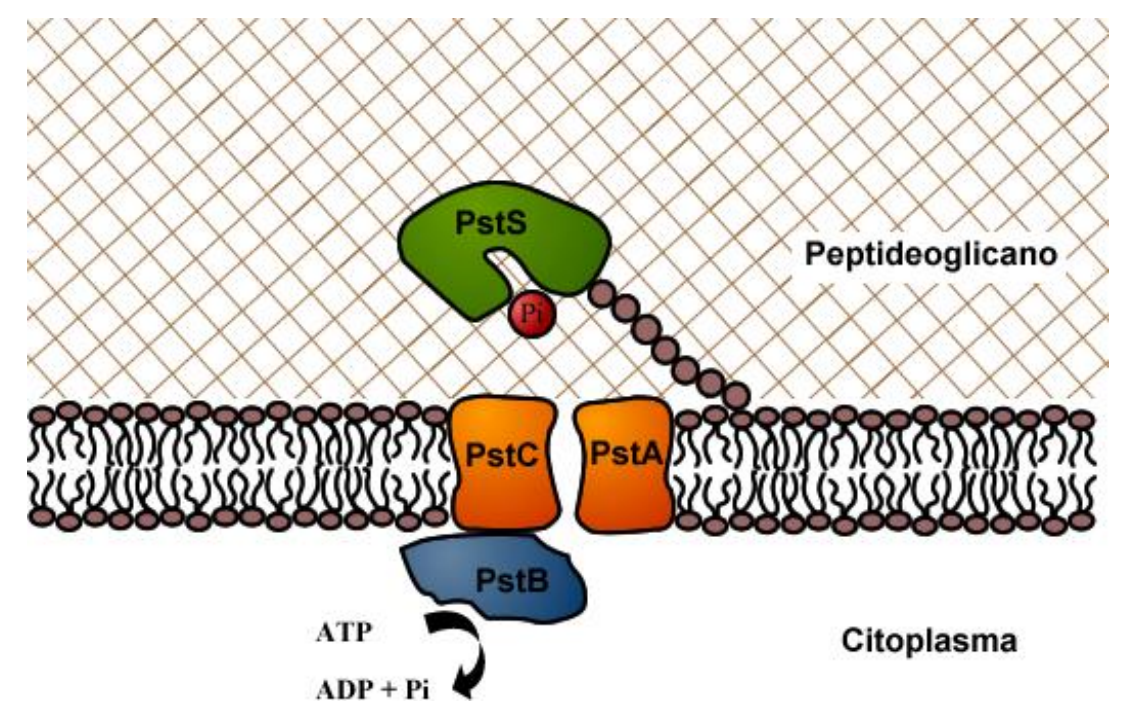

Figura 2. Componentes do sistema Pst de transporte de fosfato inorgânico em Gram-positivos. A proteína PstS é o componente ligador do sistema que interage especificamente com o fosfato inorgânico. Os componentes PstC e PstA constituem o canal transmembrânico pelo qual o fosfato será transportado para dentro da célula. O componente citoplasmático PstB é responsável por se ligar e hidrolisar ATP fornecendo energia para que o transporte ocorra. Fonte: Adaptado de Dassa, 2000.

Além da função relacionada à captação de fosfato inorgânico em condições de carência deste nutriente, o sistema Pst também está relacionado a mecanismos de virulência em diferentes patógenos bacterianos (LAMARCHE et al., 2008). Em S. pneumoniae a mutação do gene $p s t \mathrm{~B}$, além de diminuir a captação de fosfato, levou a redução da frequência de transformação e patogenicidade em modelo murino de septicemia (NOVAK et al., 1999; POLISSI et al., 1998). No caso em que o gene pstS foi inativado, houve aumento da susceptibilidade à penicilina em relação a linhagem selvagem (SOUALHINE et al., 2005).

A caracterização do sistema pst em $S$. mutans confirmou sua funcionalidade na linhagem UA159 e mostrou o papel do componente ligador deste sistema. Através da deleção do gene pst $\mathrm{S}$, bloqueando a síntese da proteína ligadora de fosfato PstS, observou-se uma diminuição da taxa de crescimento em meios com concentrações baixas ou intermediárias de fosfato, condição em que o sistema Pst deveria atuar ativamente na captação deste íon. Isto porque a ausência do componente ligador do sistema reduziu em praticamente a metade a captação de Pi extracelular, interferindo no metabolismo bacteriano. Além disso, a ausência 
da proteína PstS promoveu a redução da capacidade de adesão à superfícies abióticas cobertas com saliva e produção in vitro do polissacarídeo extracelular (PEC), fatores necessários para adesão à superfície dental (LUZ et al., 2012). 


\section{CONCLUSÕES}

A obtenção da forma recombinante da proteína PstS de $S$. mutans em sistema procarioto, a partir da fração solúvel, permitiu a preservação da estrutura da proteína e dos epítopos imunodominantes presentes na sua forma nativa.

A proteína rPstS foi capaz de estimular o sistema imune após administração sublingual, em um protocolo vacinal de mucosa, desencadeando uma resposta humoral sistêmica e local, a qual foi potencializada com a adição do adjuvante LTK4R à formulação.

Os anticorpos rPstS-específicos produzidos a partir da estratégia vacinal de mucosa foram eficientes em interferir na capacidade de colonização oral por S. mutans em modelo murino.

A proteína PstS, enquanto antígeno, é capaz de induzir geração de anticorpos com atividade neutralizante das etapas iniciais da colonização oral por S. mutans e pode ser explorada em abordagens vacinais contra a cárie dental humana. 


\section{REFERÊNCIAS*}

AJDÍC, D.; MCSHAN, W. M.; MCLAUGHLIN, R. E.; SAVIC, G.; CHANG, J.; CARSON, M. B.; PRIMEAUX, C.; TIAN, R.; KENTON, S.; JIA, H.; LIN, S.; QIAN, Y.; LI, S.; ZHU, H.; NAJAR, F.; LAI, H.; WHITE, J.; ROE, B. A.; FERRETTI, J. J. Genome sequence of Streptococcus mutans UA 159, a cariogenic dental pathogen. Proceedings of the National Academy of Sciences, v. 99, n. 22, p. 14434-14439, 2002.

AMUGUNI, J. H.; LEE, S.; KERSTEIN, K. O.; BROWN, D. W.; BELITSKY, B. R.; HERRMANN, J. E.; KEUSCH, G. T.; SONENSHEIN, A. L.; TZIPORI, S. Sublingually administered Bacillus subtilis cells expressing tetanus toxin $\mathrm{C}$ fragment induce protective systemic and mucosal antibodies against tetanus toxin in mice. Vaccine, v. 29, p. 4778-4784, 2011.

BALAN, A.; SOUZA, C. S.; MOUTRAN, A.; FERREIRA, R. C. C.; FRANCO, C. S.; RAMOS, C. H. I.; FERREIRA, L. C. F. Purification and in vitro characterization of the maltose-binding protein of the plant pathogen Xanthomonas citri. Protein Expression and Purification, v. 43, p. 103-110, 2005.

BANAS, J. A. Virulece properties of Streptococcus mutans. Frontiers in Bioscience, v. 9, p. 1267-1277, 2004.

BATISTA, M. T.; SOUZA, R. D.; FERREIRA, E. L.; ROBINETTE, R.; Crowley, P. J.; RODRIGUES, J. F.; BRADY, J.; FERREIRA, L. C. S.; FERREIRA, R. C. C. Immunogenicity and in vitro and in vivo protective effects of antibodies targeting a recombinant form of the Streptocccus mutans P1 surface protein. Infection and Immunity, v. 82, n. 12, p. 4978-4988, 2014.

BROWN, J. S.; GILLILAND, S. M.; HOLDEN, D. W. A Streptococcus pneumoniae pathogenicity island encoding $\mathrm{ABC}$ transporter involved in iron uptake and virulence. Molecular Microbiology, v. 40, n. 3, p. 572-585, 2001.

BROWN, J. S.; OGUNNIYI, A. D.; WOODROW, M. C.; HOLDEN, D. W.; PATON, J. C. Immunization with components of two iron uptake $\mathrm{ABC}$ transporters protects mice against systemic Streptococcus pneumonia infection. Infection and Immunity, v. 69, n. 11, p. 67026706, 2001.

BURNE, R. A.; SCHILLING, K.; BOWEN, W. H.; YASBIN, R. E. Expression, purification, and characterization of an exo- $\beta$-D-fructosidase of Streptococcus mutans. Journal of Bacteriology, v. 169, n. 10, p. 4507- 4517, 1987.

ÇUBURU, N.; KWEON, M.; SONG, J.; HERVOUET, C.; LUCI, C.; SUN, J.; HOLFMAN, P.; HOLMGREN, J.; ANJUERE, F.; CZERKINSKY, C. Sublingual immunization induces broad-based systemic and mucosal immune responses in mice. Vaccine, v. 25, p. 8598-8610, 2005 . 
CZERKINSKY, C.; ÇUBURU, N.; KWEON, M.; ANJUERE, F.; HOLMGREN, J. Sublingual vaccination. Human Vaccines, v. 7, p.110-114, 2011.

DASSA, E. ABC transport. In: LEDDENBERG, J. Encyclopedia of microbiology. New York: Academic Press, 2000. v.1 p. 1-12.

GARMORY, H. S.; TITBALL, R. W. ATP-Binding Cassette Transporters Are Targets for the Development of Antibacterial Vaccines and Therapies. Infection and Immunity, v. 72, n. 12, p. 6757-6763, 2004.

HAMADA, S.; SLADE H. D. Biology, immunology and carcinogenicity of Streptococcus mutans. Microbiology Review, v. 44, n. 2, p. 331-384, 1980.

HAMADA, S., KOGA, T., OOSHIMA, T. Virulence factors of Streptococcus mutans and dental caries prevention. Journal of Dental Research, v. 63, n.3, p. 407-411, 1984.

HIGGINS, C.F. ABC transporters: from microorganisms to man. Annual Review of Cell and Developmental Biology., v. 8, p. 67-113, 1992.

HIGGINS, C.F. ABC transporters: phisiology, structure and mechanism - an overview. Research in Microbiology, v. 152, n. 3-4, p. 205-210, 2001.

ITO, T.; MAEDA, T.; SENPUKU, H. Roles of salivary components in Streptococcus mutans colonization in a new animal model using NOD/SCID.e2f1 ${ }^{-/-}$mice. PlosOne, v. 7 (2): e32063. doi:10.1371/journal.pone.0032063, 2012.

KHURSHID, S.; KHALID, R.; AFZAL, M.; AKHTAR, W. Truncation of PstS1 antigen of Mycobacterium tuberculosis impoves diagnostic efficiency. Tuberculosis, v. 93, p. 654-659, 2013.

KRASTEL, K; SENADHEERA, D. B.; MAIR, R.; DOWNEY, J. S.; GOODMAN, S. D.; CVITKOVITCH, D. G. Characterization of a glutamate transporter operon, $g \ln \mathrm{QHMP}$, in Streptococcus mutans and its role in acid tolerance. Journal of Bacteriology, v. 192, n. 4, p. 984-993, 2010.

LAMARCHE, M. G.; WARNNER, B. L.; CRÉPIN, S.; HAREL, J. The phosphate regulon and bacterial virulence: a regulatory network connecting phosphate homeostasis and pathogenesis. FEMS Microbiology Reviews, v. 32, p. 461-473, 2008.

LEMOS, J. A.; QUIVEY, R. G.; KOO, H.; ABRANCHES, J. Streptococcus mutans: a new Gram-positive paradigm? Microbiology, v. 159, p. 436-445, 2013.

LINTON, K.J.; HIGGINS, C. F. The Escherichia coli ATP-binding cassete (ABC) proteins. Molecular Microbiology, v. 28, p. 5-13, 1998.

LUZ, D. E.; NEPOMUCENO, R. S. L.; SPIRA, B.; FERREIRA, R. C. C. The Pst system of Streptococcus mutans is important for phosphate transport and adhesion to abiotic surfaces. Molecular Oral Microbiology, v. 27, p. 172-181, 2012.

MICHALEK, S. M.; HIRASAWA, M.; KIYONO, H.; OCHIAI, K.; MCGHEE, J. R. Oral Ecology and virulence of Lactobacillus casei and Streptococcus mutans in gnotobiotic rats. Infection and Immunity, v. 33, n. 3, p. 690-696, 1981. 
MOUTRAN, A.; QUAGGIO, R.B.; BALAN, A.; FERREIRA, L.C.S.; FERREIRA, R.C.C. The oligopeptide (Opp) of the plant pathogen Xanthomonas axonopodis pv.citri. Current Microbiology. v. 48, n. 5, p. 354-359, 2003.

NIEMINEN, T.; KÄYHTY, H.; VIROLAINEN A.; ESKOLA J. Circulating antibody secreting cell response to parenteral pneumococcal vaccines as an indicator of salivary $\operatorname{IgA}$ antibody response. Vaccine, v. 16, p. 313-319, 1998.

NEPOMUCENO, R.S.L., TAVARES, M.B., LEMOS, J.A. ET AL. The oligopeptide (opp) gene cluster of Streptococcus mutans: identification, prevalence and characterization. Oral Microbiology Immunology, v. 22, n. 4, p. 277-284, 2007.

NOBBS, A. H.; LAMONT, R. J.;JENKINSON, H. F. Streptococcus adherence and colonization. Microbiology and Molecular Biology Reviews, v. 73, p. 407-450, 2009.

NOVAK, R.; CAUWELS, A.; CHARPENTIER, E.; TUOMANEN, E. Identification of a Streptococcus pneumoniae gene locus encoding proteins of an ABC phosphate transporter anda a two-component regulatory system. Journal of Bacteriology, v. 181, n. 4, p. 11261133, 1999.

POLISSI, A.; PONTIGGIA, A.; FERGER, G.; ALTIERI, M.; MOTLL, H.; FERRARI, L.; SIMON, D. Large-scale identification of virulence genes from Streptococcus pneumoniae. Infection and Immunity, v. 66, n. 12, p. 5620-5629, 1998.

RODRIGUES, J. F.; MATHIAS-SANTOS, C.; SBROGIO-ALMEIDA, M. E.; AMORIM, J. H.; CABRERA-CRESPO, J.; BALAN, A.; FERREIRA, L. C. S. Functional Diversity of Heat-labile Toxins (LT) Produced by Enterotoxigenic Escherichia coli (ETEC): Differential enzymatic and immunological activities of LT1 (hLT) and LT4 (pLT). The Journal of Biological Chemistry, v. 286, n. 7, pp. 5222-5233, 2011.

RUSSELL, M. W.; HAJISHENGALLIS, G.; CHILDERS, N. K.; MICHALEK, S. M. Secretory immunity in defense against cariogenic mutans streptococci. Caries Research, v. 33, p. 4-15, 1999.

RUSSELL, M. W.; CHILDERS, N. K.; MICHALEK, S. M.; SMITH, D. J.; TAUBMAN, M. A. A caries vaccine? The state of the science of immunization against dental caries. Caries Research, v.38, p. 230-235, 2004.

RUSSELL, R.R.B. Pathogenesis of oral streptococci. In: FISCHETTI, V. A.; NOVICK, R. P.; FERRETTI, J. J.; PORTNOY, D. A.; ROOD, J. I. eds. Gram-positive Pathogens. 2. ed. Washington, D. C: American Society of Microbiology, 2006. p. 332-337.

SAMBROOK, J; RUSSEL, D. W. Molecular Cloning: A Laboratory Manual. 3ed. Cold Spring Harbor Laboratory Press, 2001.

SANTACRUZ-PEREZ, C., PEGOS, V. R., HONORATO, R. V, VERLI, H., LINDAHL, E., BARBOSA, J. A. R. G., BALAN, A. A specific interdomain interaction preserves the structural and binding properties of the ModA protein from the phytopathogen Xanthomonas citri domain interaction and transport in ModA. Archives of Biochemistry and Biophysics, v. 539, n. 1, p. 20-30, 2013. 
SHIVAKUMAR, K. M.; VIDYA, S. K.; CHANDU, G. N. Dental caries vaccine. Indian Journal of Dental Research, v. 20, p. 99-106, 2009.

SMITH, D. J. Caries vaccine for the twenty-first century. Journal of Dental Education, v.67, n. 10, p. 1130-1139, 2003.

SMITH, D. J. Dental caries vaccines: prospects and concerns. Expert Reviews Vaccine, v. 9, n. 1, p. 1-3, 2010.

SOUALHINE, H.; BROCHU, V.; MÉNARD, F.; PAPADOPOULOU, B.; WEISS, K.; BERGERON, M.G.; LÉGARÉ, D.; DRUMMELSMITH, J.; OUELLETTE, M. A proteomic analysis of penicillin resistence in Streptococcus pneumoniae reveals a novel role for PstS, a subunit os the phosphate $\mathrm{ABC}$ transporter. Molecular microbiology, v. 58, n. 5, p. 1430$1440,2005$.

SWARTZ, J. R. Advances in Escherichia coli production of therapeutic proteins. Current Opinion in Biotechnology, v. 12, p. 195-201, 2001.

TANABE, M.; ATKINS, H. S.; HARLAND, D. N.; ELVIN, E. J.; STAGG, A. J.; MIRZA, O.; TITBALL, R. W.; BYRNE, B.; BROWN, K. A. The ABC transporter protein OppA provides protection against experimental Yersinia pestis infection. Infection and Immunity, v. 74, n. 6, p. 3687-3691, 2006.

TANGHE, A., P. LEFE'VRE, O. DENIS, S. D'SOUZA, M. BRAIBANT, E. LOZES, M. SINGH, D. MONTGOMERY, J. CONTENT, AND K. HUYGEN. Immunogenicity and protective efficacy of tuberculosis DNA vaccines encoding putative phosphate transport receptor. Journal of Immunology, v. 162, p.1113-1119, 1999.

TAVARES, M. B.; SILVA, B. M.; CAVALCANTE, R. C. M.; SOUZA, R. D.; LUIZ, W. B.; PACCEZ, J. D.; CROWLEY, P. J.; BRADY, L. J.; FERREIRA, L. C. S.; FERREIRA, R. C. C. Induction of neutralizing antibodies in mice immunized with an amino-terminal polypeptide of Streptococcus mutans $\mathrm{P} 1$ protein produced by a recombinant Bacillus subtilis strain. FEMS Immuology and Medical Microbiology, v. 59, p. 131-142, 2010.

VAN VEEN, H.H. Phosphate transport in prokaryotes: molecules, mediators and mechanisms. Antonie van Leeuwenhoek, v. 72, n. 4, p. 299-315, 1997.

YANG, M.; JOHNSON, A.; MURPHY, T. F. Characterization and evaluation of the Moraxella catarrhalis oligopeptide permease A as a mucosal vaccine antigen. Infection and Immunity, v. 79, n.2, p. 846-857, 2011. 